strata is ascertained, this will be precisely that quantity of water which has evaporated from the surface of the land.

The only weakness that I have been able to perceive in the conclusions which $I$ drew in 1907 regarding this

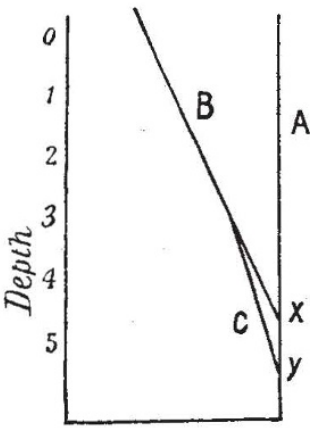

Water matter is the exact depth which was affected. This I concluded to be 7 feet in the Pusa soil. As a matter of fact, the ascertainment of this depth with exactitude is not possible. In the marginally shown diagram are three curves. A represents the water immediately after rain ceases (in an ideal physically uniform soil). B represents the water as ascertained at the conclusion of the dry period, and cuts $\mathrm{A}$ at the point $x$, below which no decrease of water has been perceptible by the methods employed. Owing, however, to errors, due principally to difference of physical character of soil, this point cannot be. determined exactly, and in reality the curve might be $\mathrm{BC}$, that is, it might cut $\mathrm{A}$ at, say, $y$, and not at $x$; but the difference between the ascertained loss and the real loss can only be trifling. I is perhaps needless to add that this error does not affect the principles involved. It is naturally assumed that the points $x$ and $y$ are above the stratum of soil which is maintained in a saturated condition by the underground water.

Pusa, Bengal, November 23, 1908 . J. Walter Leather.

Dr. Leather is no doubt correct in supposing that the upward movement of water through the soil is gradual, and in his further deduction that there must, for a time, be some strata in which the water has not yet begun to move; but we do not know the velocity at which water travels upwards in the soil, and consequently one cannot say whether the time during which any particular stratum remains unaffected is to be measured in days or months Dr. Leather's results do not give the velocity of upward movement, but the difference between the loss and the gain of water at different depths. It is no more possible to calculate the amount of water that has passed through a particular stratum by determining the amounts present at two different times than it would be to calculate the quantity of heat passing along a rod of unknown thermal properties by measuring the temperature change at a particular point.

The great value of Dr. Leather's results lies in the fact that they are the most complete set of moisture determinations yet made under conditions of drought. If only some physicist could be induced to turn his attention to soil problems he would find these data very useful.

The Rothamsted Laboratories, Harpenden, Herts.

$$
\text { E. J. Russel }
$$

\section{The Correlation of Teaching.}

Tine valuable summary of Prof. Perry's address to the "correlation" conference given in NATURE of December 3, 1908 (p. 143), contains the following statement:- "If a boy wrote a description of anything he had done in a laboratory or elsewhere, it should be an exercise in English." This is, unfortunately, accepted by educationists at the present time. Can Prof. Perry not aid in breaking down this barrier to progress rather than in fixing its joints more firmly? He has done so much, cannot he do more?

I would suggest, whether in class-room exercises or in examinations, that the boy's resultant essay should be examined and corrected by the examiner without reference to spelling, writing, grammar, \&c. The object should surely be to put on paper what has been learnt about the subject in hand. Spelling being the result of the use of accurate vision, writing being the result of physical and nervous stability, need in no circumstances affect the value of a scientific production. As the boy gets older and as his view of life extends, the value of his production, from the point of view of English, will gradually improve.

Besides, it is nothing short of an absurdity to look at certain exercise books, where the red-ink corrections, that have taken so much of the teacher's time, are chiefly connected with something that in no way affects the value of the exercise itself.

December 3I, 1908 .

I AGREE with Mr. Woods in his condemnation of a system in which every exercise is treated as if grammar and composition were as important as the subject-matter; but surely he is going too far when he says that in writing a description of what he has done or seen, a boy need not fear that his grammar or spelling or composition will be criticised at all. I ask the science master, in teaching science, to teach also mathematics and English and sketching incidentally, and to take some pleasure in doing it. If he insists that these subjects are the absolute preserves of the mathematical, the English, and the drawing masters, he must not be astonished when a classical master openly expresses pride in an ignorance of "stinks."

I do not think that the system which Mr. Woods condemns is very much in vogue, whereas the system of which he approves has done an immense amount of harm. We all of us know men holding the highest science degrees whose spelling, grammar, and composition are beneath the contempt of a board-school boy. In nine cases out of ten it will be found that when a student cannot give a clear account of what he has seen or done, he has no clear ideas about the matter, and every examiner knows that it is only the very exceptional man who has clear knowledge yet cannot express himself clearly. If the examiner has a keen sense of justice this candidate gives him more trouble than any five others. Jorn Perry.

\section{An Electromagnetic Problem.}

The problem noticed by $\mathrm{Mr}$. Comstock in NAtUre of November 19, 1908, is an interesting one, but I do not see how the "laws of electricity and conservation of energy require in themselves the discrete structure of electricity or the association of electricity with matter." The electromagnetic field produced by a uniform spherical sheet of electricity, unassociated with matter expanding under its own repulsion, is not zero, but indeterminate. The total energy of the system remains finite and constant, while the velocity of expansion is that of light. Thus perfect uniformity of electricity, together with isolation, is not incompatible with the laws of electricity and conservation of energy. The indeterminateness of the electromagnetic field will, of course, surprise no one who is willing to start with a distribution of electricity differing infinitely little from that of perfect uniformity, arranged as a sheet differing infinitely little from spherical, and expanding in surroundings departing infinitely little from the symmetrical.

A. Core.

Mr. CoRE's objection would apply in many problems where certain functions appear to vanish because of symmetry, but in the present case I think it does not apply. In physical problems it is well to avoid mathematical " sheets" except in unusually simple circumstances, and in the present case the spherical shell of electricity which is expanding under the mutual repulsion of its parts is to be considered of finite thickness and of constant volume density of electricity.

In these circumstances the displacement current is evidently equal and opposite to the convection current when the sphere is expanding, and hence the curl of the magnetic force is zero everywhere. This requires the magnetic force to be zero everywhere, since such a vector vanishing at infinity and having its curl and divergence both zero must itself vanish. It is not then immediately evident what becomes of the electrical energy lost on expansion.

D. F. Сомsтоск.

Institute of Technology, Boston, December I7, I908. 